\title{
Strategic Issues in Product Recovery Management
}

\author{
Martijn Thierry \\ Marc Salomon \\ Jo Van Nunen \\ Luk Van Wassenhove
}

$\mathrm{P}$

roduct recovery management (PRM) encompasses the management of all used and discarded products, components, and materials that fall under the responsibility of a manufacturing company. The objective of product recovery management is to recover as much of the economic (and ecological) value as reasonably possible, thereby reducing the ultimate quantities of waste.

The traditional approach of many manufacturers towards used products has been to ignore them. Manufacturers typically did not feel responsible for what happened with their products after customer use. Most products were designed in such a way that while materials, assembly, and distribution costs were minimized, the repair, reuse, and disposal requirements were not taken into account. Manufacturers generally believed that the costs of incorporating these requirements would outweigh the benefits. Most of their customers were not prepared to pay an additional fee for a "green" product. Most purchasing decisions were made with the intention of minimizing the purchasing costs, instead of optimizing life-cycle performance-which includes maintenance, reuse, and disposal issues. Consequently, the majority of used products in "developed countries" were landfilled or incinerated, with considerable damage to the environment.

Today, both customers and authorities demand that manufacturers reduce the quantities of waste generated by their products. Customer pressure is triggered by environmental concern in general and by rising product disposal costs

The first author was supported by NWO (Dutch Foundation for Scientific Research) in NFI-80 DSS program. The authors also acknowledge the financial support of INSEAD (Research project $2042 \mathrm{C}$ : Remanufacturing and Recycling from a Business Perspective). 
in specific. Product disposal costs have increased significantly in recent years as landfill and incineration capacity is being depleted. Governmental action encompasses both legislation and purchasing programs. Legislative actions include disposal bans for specific products (e.g., appliances), recycled content mandates, recycling goals, and product take-back requirements. Purchasing programs favor products that are reusable or that have reused content.' Unfortunately, the contents of legislation and purchasing programs differ by country, or even by state within a specific country. This poses considerable problems to manufacturers that compete on a worldwide scale. A number of well-known international manufacturers (including Shape, 3M, and Xerox) have decided to manufacture their products according to (or beyond) the highest existing environmental standards. ${ }^{2}$

Many companies consider the issue of discarded products a threat to their business. Clearly, complying with rapidly changing regulations and fulfilling fast moving customer demands may require a fundamental change in doing business. However, there could be large opportunities for companies that succeed in ways of embodying current and future environmental demands in their business policy. For instance, by offering "green products," companies could attract and retain environmentally conscious customers and employees. Producing greener products could lower future liabilities, insurance rates, and customers' disposal costs. Pro-active companies could influence the formation of new legislation and avoid taking costly last-minute actions. Finally, companies could use discarded products as a valuable source of components and materials. These considerations indicate the necessity for manufacturing companies to develop an effective PRM policy.

\section{PRM Options and the Acquisition of Information}

Analyzing these PRM opportunities and threats should be the first step for any company that is (forced to get) involved in PRM. However, many companies find that the acquisition of the data required to make accurate analyses on PRM issues is problematic. Frequently, relevant data are scattered throughout the company, dispersed across companies in the business chain, or not available at all. In the case of PRM, the relevant business chain includes repair centers, reprocessors, and waste management companies.

Required information can be classified into four categories:

- information on the composition of products;

- information on the magnitude and uncertainty of return flows;

- information on markets for reprocessed products, components, and materials; and

- information on actual product recovery and waste management operations. 


\section{Products}

The first category of information entails the composition of manufactured products. Compiling information involves an analysis of the different material types, their relative quantities, their value, their potentially hazardous nature, and the way in which different components and different materials are fastened and combined. It also includes analysis of the technical feasibility of different product recovery options. Additionally, specific legislative requirements for individual products, components, and materials must be determined. A number of automobile manufacturers, such as BMW and VW, have set up pilot plants to examine reusability of current models and to develop design requirements for new models. ${ }^{3}$

\section{Magnitude and Uncertainty of Return Flows}

The second category of information involves the "supply-side" of used products, components, and materials. Manufacturers need to examine the magnitude and uncertainties attached to each type of return flow. Each type of return flow may have different characteristics. One return flow type is that manufacturers could be required by law or by contract to take back used products. For instance, VW and Opel have been selling some of their 1992 models in Germany with the guarantee that they will take back their products at the end of their lives at no charge to the customer. ${ }^{4}$ We expect that it will be hard for companies like VW and Opel to accurately predict the "supply" of used cars as it includes the need to estimate the number of cars that end their "lives" outside Germany (e.g., in Africa).

Off-lease and off-rent products constitute another type of return flows. A significant number of lease and rental contracts specify that manufacturers take back products upon contract expiry. In most cases, manufacturers are able to predict the quantities and timing of these return flows quite accurately. Making reliable estimations about the quality of these products can nevertheless be quite difficult.

Products with technical failure form yet another type of return flow. Quantities of product returns depend on service contracts, product warranties, and the ability to repair products at the customer's location. The ability to forecast return flows of defective products depends on the nature of the products. For instance, electronic components tend to follow a random failure pattern over time, whereas mechanical components often tend to wear out with age.

A limited number of manufacturers "buy-back" used products and components from their customers or used products' brokers. Buying back used products can have three advantages. First, manufacturers may acquire an inexpensive source of components and materials for service or manufacturing purposes. Second, customers' disposal costs for landfilling and incineration can be reduced. Third, buying-back used products could provide manufacturers with the opportunity to sell or lease new products. The ability to predict return flows 
in this case depends on the ability of the manufacturer to set accurate buy-back prices.

For each type of return flow, manufacturers must make an assessment of the expected quantities, quality, timing, and locations of return. This assessment gives manufacturers insight in the "supply-side" of used products.

\section{Markets for Reprocessed Products and Materials}

Finding markets for used products can be very hard. The acceptance of used products in the marketplace depends basically on the perceived differences in quality and costs between used and "virgin" products or materials. Manufacturers must make a "demand-side" assessment by examining potential markets for each of the product recovery options. Products and materials can be reused

- by the company itself,

- by other companies (e.g., suppliers) in the business chain, or

- by companies outside the business chain.

\section{Actual Product Recovery and Waste Management Operations}

Analysis of current product recovery and waste management operations includes examination of:

- which organizations are involved,

- which obstacles occur (if any),

- which quantities of products are processed (for each product recovery and waste management option),

- costs and revenues, and

- the environmental impact of the entire process.

Some manufacturers have found that cooperation with chain members can provide them with this information. IBM UK, for example, cooperates with Mann Organization, a UK-based equipment reprocessor.

Since 1991, IBM UK has offered to take back used IBM equipment from any source. The company has outsourced the product recovery operations to Mann Organization. This organization reports back to IBM UK on the difficulties of product recovery and thus has an influence on IBM equipment design. ${ }^{5}$

\section{Product Recovery Options}

Figure 1 presents an integrated supply chain where service, product recovery, and waste management activities are included. Returned products and components can be resold directly, recovered, or disposed (incinerated or landfilled). The five product recovery options are: repair, refurbishing, remanufacturing, cannibalization, and recycling. The options are listed in order of the required degree of disassembly (teardown). All options are suitable for both products and components. 


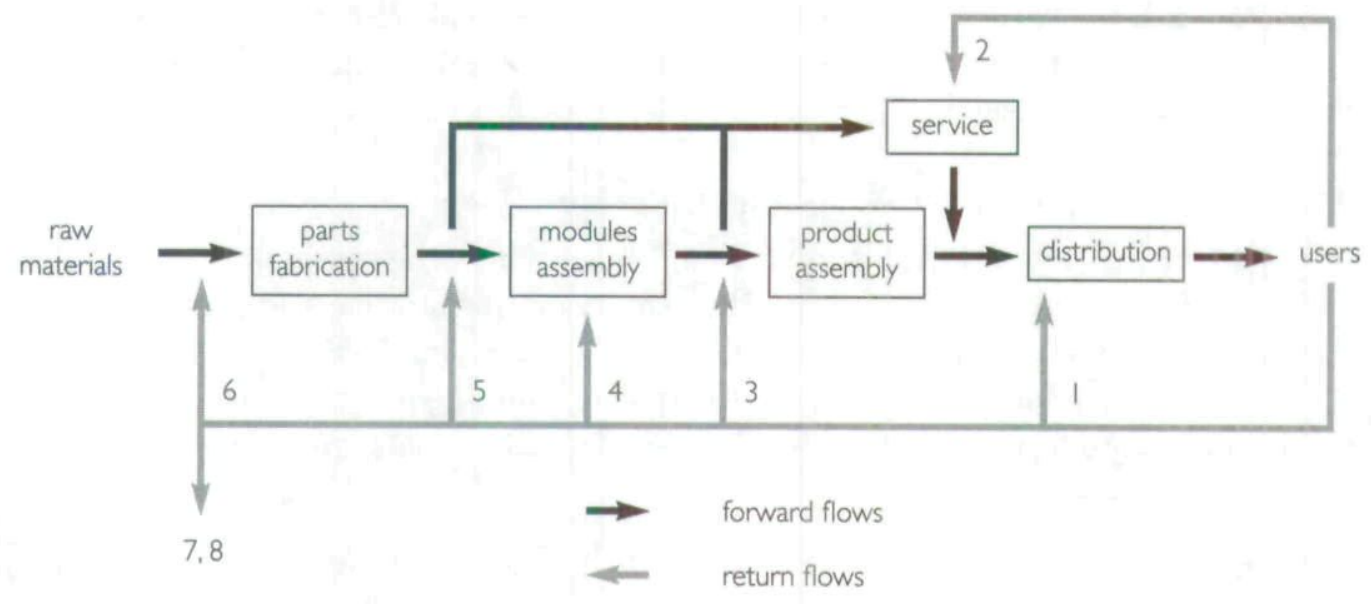

\section{Waste Management}

\section{Product Recovery Management}

\section{Direct Reuse}

\author{
2: Repair \\ 3 : Refurbishing \\ 4 : Remanufacturing
}

I : Direct reuse/ resale

Each of the product recovery options involves collection of used products and components, reprocessing, and redistribution. The main difference between the options is in reprocessing. Hence, we concentrate on the reprocessing process in the description of the different product recovery options.

Repair, refurbishing, and remanufacturing "upgrade" used products in quality and/or technology. These options differ with respect to the degree of upgrading. Repair involves the least, and remanufacturing the largest increase.

\section{Repair}

The purpose of repair is to return used products to "working order." The quality of repaired products is generally less than the quality of new products. Product repair involves the fixing and/or replacement of broken parts. Other parts are basically not affected. Repair usually requires only limited product disassembly and reassembly. Repair operations can be performed at the customer's location or at manufacturer-controlled repair centers. A large number of durable products manufacturers (e.g., IBM, DEC, and Philips) are engaged in product repair. 


\section{Refurbishing}

The purpose of refurbishing is to bring used products up to specified quality. Quality standards are less rigorous than those for new products. Following disassembly of used products into modules, all critical modules are inspected and fixed or replaced. Approved modules are reassembled into refurbished products. Occasionally, refurbishing is combined with technology upgrading by replacing outdated modules and parts with technologically superior ones. Military and commercial aircraft are examples of products that are refurbished. Refurbishing significantly improves their quality and extends their service-life. However, remaining service-life is generally less than the average service-life of new aircraft.

\section{Remanufacturing}

The purpose of remanufacturing is to bring used products up to quality standards that are as rigorous as those for new products. Used products are completely disassembled and all modules and parts are extensively inspected. Worn-out or outdated parts and modules are replaced with new ones. Repairable parts and modules are fixed and extensively tested. Approved parts are sub-assembled into modules and subsequently assembled into remanufactured products. Remanufacturing can be combined with technological upgrading. For example, a used machine tool can often be upgraded to "as new" quality and technology for $50-60 \%$ of the cost of a new machine. ${ }^{6}$ BMW has been remanufacturing high-value components such as engines, starter motors, and alternators for a number of years. The remanufactured components are tested according to strict quality standards to become a BMW Exchange Part. Exchange Parts are resold, with the same quality and warranty, at a price $30-50 \%$ cheaper than new parts. ${ }^{7}$

\section{Cannibalization}

In the first three product recovery options, a large proportion of used products is being reused. In cannibalization, only a small proportion is being reused. The purpose of cannibalization is to recover a limited set of reusable parts from used products or components. These parts are reused in repair, refurbishing, or remanufacturing of other products and components. Quality standards for cannibalized parts depend on the process in which they will be reused. Parts for remanufacturing have to fulfill stricter quality standards than parts for refurbishing or repair. Cannibalization involves selective disassembly of used products and inspection of potentially reusable parts. The remaining parts and modules are not used in cannibalization. For example, Aurora, a U.S. company, is mainly engaged in cannibalizing integrated circuits. The company pulls off the parts they want from a computer and tests, straightens, redips, polishes, and sells the chips. Sales have grown from zero to more than $\$ 40$ million between 1988 and $1993 .{ }^{8}$ 


\section{Recycling}

The goal of the previous product recovery options is to retain the identity and functionality of used products and their components as much as possible. In recycling, the identity and functionality of products and components is lost. The purpose of recycling is to reuse materials from used products and components. These materials can be reused in production of original parts if the quality of materials is high, or else in production of other parts. Recycling begins when used products and components are disassembled into parts. These parts are separated into distinct material categories. These separated materials are subsequently reused in the production of new parts. Recycling is currently being applied to a number of used products. For example, virtually all metals in discarded cars (on average $75 \%$ of the weight of a car) are being recycled in Western countries like Germany, the UK, and the United States. ${ }^{9}$

Different characteristics of, and main differences between, the product recovery options are summarized in Table 1.

TABLE I. Comparison Between Product Recovery Options

\begin{tabular}{|c|c|c|c|}
\hline & $\begin{array}{l}\text { Level of } \\
\text { Disassembly }\end{array}$ & $\begin{array}{l}\text { Quality } \\
\text { Requirements }\end{array}$ & $\begin{array}{l}\text { Resulting } \\
\text { Product }\end{array}$ \\
\hline Repair & To product level & $\begin{array}{l}\text { Restore product to } \\
\text { working order }\end{array}$ & $\begin{array}{l}\text { Some parts fixed or } \\
\text { replaced by spares }\end{array}$ \\
\hline Refurbishing & To module level & $\begin{array}{l}\text { Inspect all critical } \\
\text { modules and upgrade } \\
\text { to specified quality level }\end{array}$ & $\begin{array}{l}\text { Some modules } \\
\text { repaired/ replaced: } \\
\text { potential upgrade }\end{array}$ \\
\hline Remanufacturing & To part level & $\begin{array}{l}\text { Inspect all modules and } \\
\text { parts and upgrade to as } \\
\text { new quality }\end{array}$ & $\begin{array}{l}\text { Used and new } \\
\text { modules/parts } \\
\text { combined into new } \\
\text { product; potential } \\
\text { upgrade }\end{array}$ \\
\hline Cannibalization & $\begin{array}{l}\text { Selective retrieval of } \\
\text { parts. }\end{array}$ & $\begin{array}{l}\text { Depends on process in } \\
\text { which parts are reused }\end{array}$ & $\begin{array}{l}\text { Some parts reused; } \\
\text { remaining product } \\
\text { recycled/disposed }\end{array}$ \\
\hline Recycling & To material level & $\begin{array}{l}\text { High for production of } \\
\text { original parts; less for } \\
\text { other parts }\end{array}$ & $\begin{array}{l}\text { Materials reused to } \\
\text { produce new parts }\end{array}$ \\
\hline
\end{tabular}

Figure 2 gives an integrated view of the different PRM options: repair in column 1; refurbishing starting in column 2; remanufacturing starting in column 2 but entering column 3 when modules are disassembled into parts; cannibalization in column 3; and recycling in column 4.

Figure 2 shows the interactions between the different options. For instance, modules that are rejected for remanufacturing might be suitable for 
FIGURE 2. An Integrated View of Product Recovery Activities




cannibalization. Parts rejected for cannibalization might be appropriate for recycling. Figure 2 also indicates potential "markets" for reprocessed materials, components (modules and parts), and products. Recyclable materials can be used to fabricate (original or other) parts, or be sold to other companies. Approved parts and modules can be used to manufacture modules and products, employed as spare parts and modules, or sold to other companies (not depicted). Ultimately, a small percentage of the contents of returned used products (typically less than $10 \%$ for pro-active PRM manufacturers) still has to be disposed of.

Which product recovery option is selected depends on: technical feasibility; supply of suitable used products and components; demand for reprocessed products, components, or materials; and economic and environmental costs and benefits.

Products and materials may go through a sequence of different phases in their life. GE Plastics is experimenting with extending the life of a bumper through four successive phases: grinding it to become raw material for an internal automotive component; regrinding it to become an ingredient for a plastic bench; recycling it into a building material; and designating it as fuel for incinerators. ${ }^{10}$

Following is a case study based on the situation of a multinational copier manufacturer (nicknamed "CopyMagic") that has been involved in product recovery management for a number of years. This case study illustrates a selected set of strategic production and operations management issues in product recovery management.

\section{Case Study: CopyMagic}

CopyMagic is a multinational copier manufacturer that sells a number of different products in all segments of the copier market. Leasing of copiers is the most popular. Competition in the copier market is predominantly on priceper-copy, product reliability, product features, and customer service.

Figure 3 shows the structure of CopyMagic's network. All products are assembled by CopyMagic itself out of a small number of modules. Assembly operations are carried out in factories located in Europe. Each product family is assembled on a separate assembly line. Products of a specific product family are assembled in one factory only. The factories engage in the sub-assembly of a limited number of modules. Each module consists of a large number of parts. The factories are responsible for the procurement of all parts and of all modules that are not produced by CopyMagic.

Operating Companies (OPCOs), located in all major European countries, are responsible for the marketing, sale, and lease of CopyMagic's products. OPCOs are also responsible for providing (technical) service to CopyMagic's customers. OPCOs are managed as independent profit centers. Inventories of spare 
parts, required to repair failed products, are held locally by the OPCOs and their service engineers and centrally by the Central Logistics Center (CLC).

Located in one of the European countries, the CLC is responsible for all inbound and outbound logistics activities. This includes the management of all transportation of parts and modules from suppliers to factories and the distribution of all finished products and spare parts to the OPCOs and their customers. Additionally, the CLC is the main storage center for inbound parts and modules and outbound products and spare parts.

CopyMagic not only brings new products to markets, but also takes back used products from its customers. The majority of the return flows are off-lease products. These are products that CopyMagic has to take back from its customers after expiry of their lease contracts. These products are returned to the OPCOs. A small part of the return flows consists of demonstration models, copiers that have been used by CopyMagic itself, and copiers with technical failure.

In this case study, we focus on the product recovery management system that CopyMagic has set up for its used products. Currently, CopyMagic operates an extensive product recovery management system that encompasses remanufacturing, recycling, cannibalization, and repair operations. As we want to assess the influence of each of these reprocessing activities on the company, we have simplified the situation by assuming that CopyMagic has gone through four separate phases in the processing of its used products. In reality, this is not what happened (the phases were much more integrated), but it allows us to analyze the effects of each option more clearly. Table 2 shows the different phases in CopyMagic's product recovery management. In what fol-

TABLE 2. Different Phases in Product Recovery Management

\begin{tabular}{|c|c|}
\hline Phase & Product recovery options \\
\hline I & Repair \\
\hline 2 & Repair + Cannibalization \\
\hline 3 & Repair + Cannibalization + Recycling \\
\hline 4 & $\begin{array}{l}\text { Repair + Cannibalization + Recycling } \\
+ \text { Remanufacturing }\end{array}$ \\
\hline
\end{tabular}
lows, we look at the specific characteristics of repair, cannibalization, recycling, and remanufacturing operations.

\section{Repair}

PRM activities in this first phase were limited to product and component repair. Whereas previously all copiers were disposed of, all copiers are now taken back by the OPCOs. Although most copiers are disposed of immediately, some are repaired to serve as (temporary) replacement for failed products and components.

CopyMagic originally decided to select the OPCOs as the primary sites for repair for two reasons. First, OPCOs already received the bulk of returned 
FIGURE 3. Original Situation

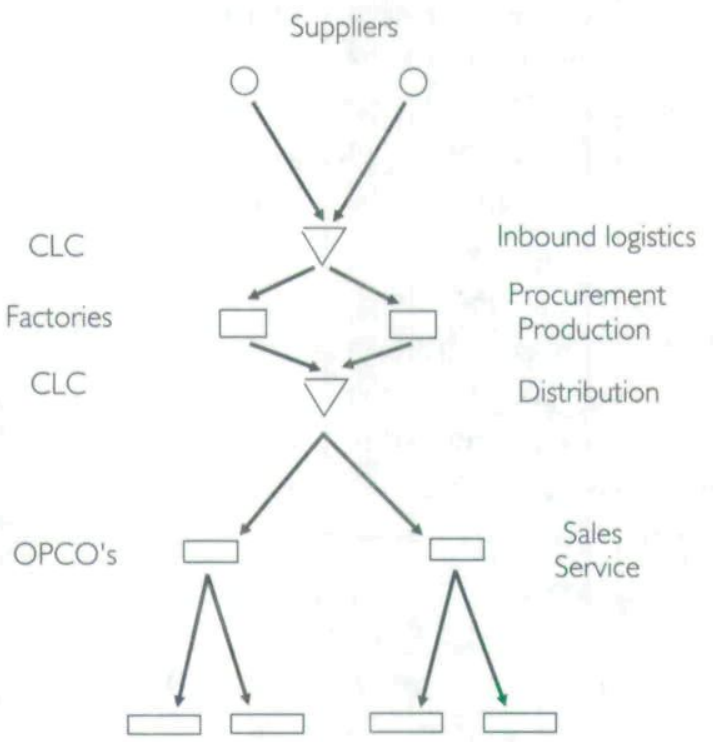

Customers
FIGURE 4. Phase | \& 2

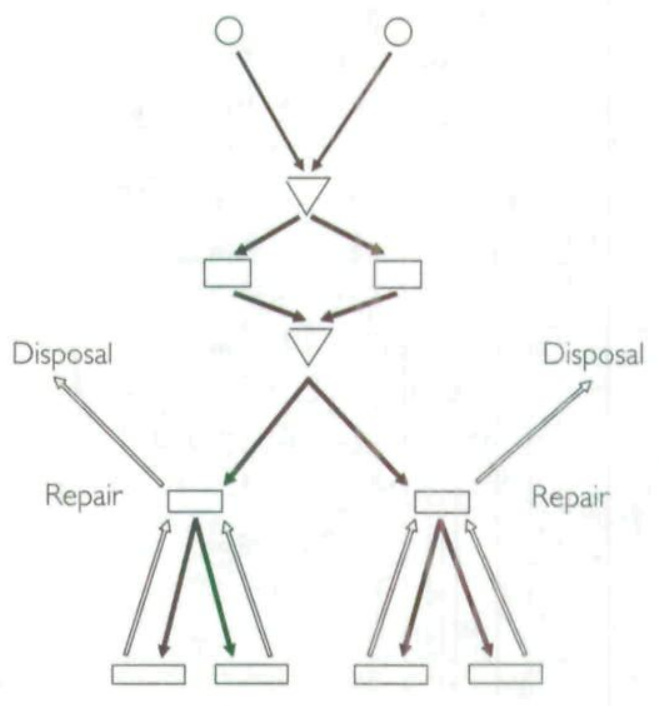

FIGURE 6. Phase 4

FIGURE 5. Phase 3

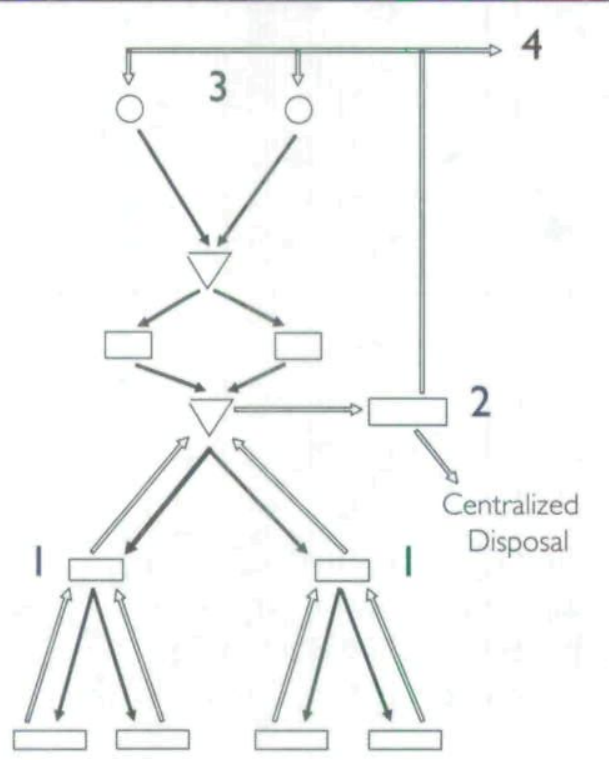

I : Repair \& cannibalization

2 : Separation

3 : Internal recycling

4 : External recycling
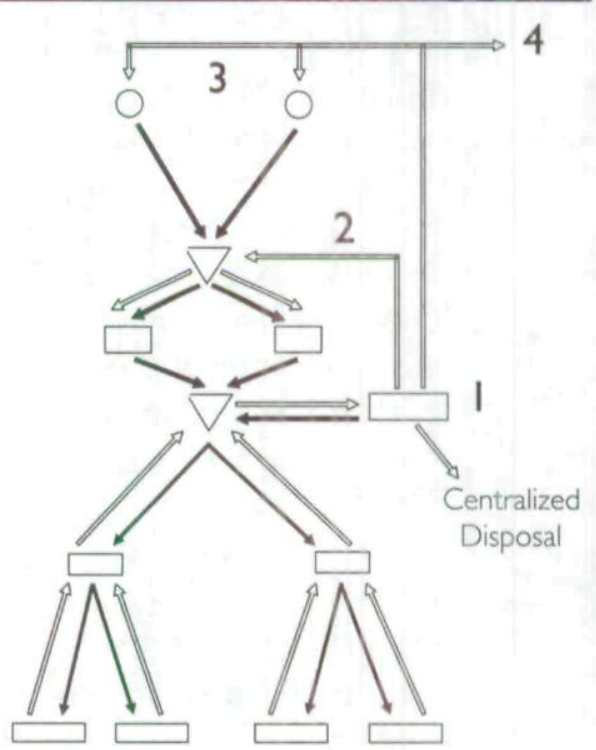

1 : Categorization, repair, cannibalization \& separation

2 : Equipment for remanufacturing

3: Internal recycling

4 : External recycling 
products and components. Second, service engineers at the OPCOs already had considerable experience in product and component repair.

The repair process did require additional spare parts to replace failed components. These spare parts were periodically shipped from the CLC to the OPCOs. Lead-times of spare parts could be very long (more than 4 weeks) when the CLC had gone "out of stock" due to unforeseen spare part demand. Consequently, OPCOs had to maintain large (expensive) inventories of spare parts in order to guarantee service. Figure 4 shows the structure of CopyMagic's network in this phase.

\section{Cannibalization}

In the previous phase, the OPCOs were occasionally having problems with the supply of spare parts. These problems stimulated the OPCOs to engage in cannibalization of used (non-repairable or excess) products and components.

Cannibalization reduced the need for "new" spare parts and decreased the amount of non-reusable waste. Cannibalization operations were quite simple. They consisted of partial disassembly of the used products; retrieval of potentially useful parts; and testing of the retrieved parts. The potential reduction in waste by means of cannibalization was limited. Typically, less than $10 \%$ of the contents of used products was reused through cannibalization. The remaining fraction still had to be disposed of. All cannibalization activities were carried out at the OPCOs. Figure 4 represents this network structure.

\section{Recycling}

The quantities of disposed products and components in the previous phases were considerable. As most of the used products' contents were not reused in any way, CopyMagic decided to engage in recycling of previously disposed products and components.

The implementation of recycling involved a number of changes for CopyMagic. First, CopyMagic had to change the design requirements for its products. Design requirements for recycling included the following aspects: design for disassembly, standardization of materials, and increasing the recycled content of products and components. Originally, CopyMagic did not design products according to these principles. This resulted in products that could hardly be recycled. CopyMagic's design for disassembly focused on improved fastening methods and avoidance of non-separable parts and materials. In addition, CopyMagic concentrated on reducing and standardizing the different types of materials in its products. Fewer material types simplified recycling operations and made the recycling process more cost-effective. Non-recyclable materials were replaced with recyclable materials as much as reasonably possible. Materials were selected on the basis on life-cycle costs and performance instead of purchasing and manufacturing costs only. 
Separation and sorting of materials was greatly enhanced by the coding of materials in CopyMagic's products. This was especially true for plastics. Without coding, it was very difficult and expensive to separate and sort the different types of plastics. Additionally, CopyMagic increased the recycled content of its products. Finding markets for recycled materials is notoriously hard. Reusing these materials in manufacturing new products provides a (partial) solution for this problem, providing the quality of the materials is "as good as new" and the customers accept the use of recycled materials. An important effect of design for recycling was increased repairability. Due to easier disassembly, repair operations became simpler and more cost-effective.

Second, CopyMagic had to determine which recycling activities it would perform in-house. As CopyMagic had limited experience in parts fabrication, it decided to perform all disassembly, separation, sorting, and cleaning activities inhouse but to outsource all parts fabrication activities. CopyMagic's experience in product assembly and knowledge on the composition of products facilitated execution of the in-house activities.

CopyMagic used recycling in the "green marketing" of its products. At the same time, CopyMagic had to convince its customers that products containing recycled materials still fulfilled all requirements with respect to product quality.

Relations between CopyMagic and its suppliers changed in this phase. First, the number of suppliers decreased as CopyMagic standardized the different types of materials. Second, all suppliers were required to code materials according to CopyMagic's standards. Industry standards are being developed. Third, suppliers became more involved in CopyMagic's product design process by providing useful advice on product recyclability.

Finally, the relation between CopyMagic and some of its suppliers (the recycling companies) changed to a "two-way relation." In addition to being a buyer of new parts, CopyMagic became a seller of used materials. In addition to being sellers of new parts, these suppliers became buyers of used materials.

Figure 5 gives an overview of the different forward and reverse flows in this phase. Repair and cannibalization operations were still performed by the OPCOs. All non-repairable and excess equipment were transported from OPCOs to a Central Recovery Center (CRC) located close to the CLC. Transportation of used equipment between the OPCOs and the CRC used the same trucks that brought new equipment from the CLC to the OPCOs. All disassembly, separation, sorting and cleaning activities were performed at the CRC. Sorted and cleaned materials were transported to existing suppliers ("3" in Figure 5) or to other companies (" 4 " in Figure 5). Reasons for centralizing these operations were threefold: faster learning by experience; higher utilization of capacity; and better coordinated and more cost-effective transportation both of recyclable materials to recycling companies and of disposable materials to disposal sites. 


\section{Remanufacturing}

Although recycling considerably reduced the amount of waste generated, CopyMagic decided to go one step further. In addition to reusing materials (recycling), it decided to reuse components in making products that fulfill all quality standards for new products (remanufacturing). Potential benefits of remanufacturing are: a reduction in material costs for parts and modules; a reduction in energy costs; a reduction in product disposal costs; and a reduction in the overall environmental impact.

Today, CopyMagic is engaged in two forms of remanufacturing: remanufacturing with the addition of new technology, and remanufacturing without the addition of new technology. Addition of new technology is usually done by replacing outdated modules and parts with superior new ones, and/or by adding new software or control systems. Technological upgrading is especially applied when new products with more advanced technology have been introduced.

Design requirements for remanufacturing include: product disassembly, standardization of components, coding of products and components, and modular design. These requirements are very similar to recycling requirements, the major difference being that remanufacturing focuses on components whereas recycling focuses on materials. Standardization of components facilitates remanufacturing since used components can be reused in several types of products. Coding of products and components is useful to monitor the condition of the products and components over time, and to identify the number of times components have been reused. Modular design enables separate development and testing, and stimulates easy disassembly.

CopyMagic decided to perform all remanufacturing operations in-house. Being the "original equipment manufacturer," it has a natural advantage over third parties. CopyMagic decided to perform the remanufacturing operations at the factories where the new products of the same type are produced. In this way, remanufactured and "new build" products can use the same assembly lines, equipment, and operators. Start-up costs for remanufacturing were low, but production planning and control became more complex.

Remanufacturing did require new skills and equipment that were not necessarily available-e.g., to perform testing, repair, and quality control operations. In remanufacturing, quality control is essential as all used products are likely to have some defects.

Since the quality of the remanufactured products is "as good as new," these products are treated in the same way as new products: similar warranties, similar service contracts. Lease prices for both product categories are identical. Sale prices of remanufactured products are somewhat lower than new products' sale prices. Remanufactured products are distributed through the same channels as new products, using the same transportation equipment and distribution facilities. 
Remanufacturing has enhanced CopyMagic's "green image" in the market, but the company has had to put much effort in its marketing operations to convince its customers that the quality of remanufactured products is indeed "as good as new."

Supplier relations are also affected by remanufacturing. Successful remanufacturing significantly reduces the need for outside procurement of parts and modules. There seems to be an interesting paradox. Suppliers that make the best components may lose most business (in comparison with other suppliers) since their components can be reused more often. Companies have to solve this "paradox" if they want to engage in remanufacturing. Analogous to the previous phase, the number of component suppliers has been reduced as CopyMagic has standardized its components. All suppliers are required to code components in the same way as CopyMagic does.

Benefits of remanufacturing are largest when companies are able to forecast (and control) the distribution (magnitude and timing) and quality of the return flows of used products. The high share of lease contracts (usually with a fixed contract length) has enabled CopyMagic to predict these return flows quite accurately. Occasionally, OPCOs buy-back used products from former customers when supply of suitable used products is below schedule. Nevertheless, CopyMagic has had to set up new information systems to forecast, monitor, and analyze the return flows of used products and the behavior of remanufactured products, modules, and parts "in the field."

Figure 6 shows the structure of the forward and reverse flows. Management of all reverse flows has now been centralized at the CRC. Centralization has improved integrated control of all product recovery management processes. All return flows are sent from the OPCOs to the CRC (in the same trucks that are used for the distribution of new products). Here, all used products are inspected and categorized into four groups: repair, remanufacturing, cannibalization, and recycling. The first group encompasses products that have been used for a (very) short time. These products are repaired centrally and sent back to the OPCOs (" 1 " in Figure 6). They are primarily used as (temporary) replacement for failed copiers. The second group encompasses products that will undergo remanufacturing operations. These products are shipped from the central reprocessing location to the factories where they are remanufactured into original or technologically upgraded products ("2" in Figure 6). The third group encompasses those products that are "beyond repair or remanufacturing." Cannibalization of these products is performed at the central reprocessing location. Reusable components are removed from the products, put into storage at the CLC, and reused in repair, remanufacturing or service operations. The last group encompasses the products that are recycled by "internal" ("3" in Figure 6) and "external" companies ("4" in Figure 6). Ultimately, a small fraction of the used products (less than 10\%) still has to be disposed of. 
TABLE 3. Characteristics of Different Product Recovery Phases at CopyMagic

\begin{tabular}{|c|c|c|}
\hline & Phase I & Phase 2 \\
\hline Customer relations & Hardly affected & Hardly affected \\
\hline Supplier relations & Hardly affected & Hardly affected \\
\hline \multirow[t]{2}{*}{ Network structure } & $\begin{array}{l}\text { Decentralized repair in OPCOs } \\
\text { Decentralized disposal }\end{array}$ & $\begin{array}{l}\text { Decentralized repair and } \\
\text { cannibalization in OPCOs } \\
\text { Decentralized disposal }\end{array}$ \\
\hline & Phase 3 & Phase 4 \\
\hline Customer relations & $\begin{array}{l}\text { Green marketing } \\
\text { Manage quality perception of } \\
\text { customers } \\
\text { Suppliers become buyers of } \\
\text { recyclable materials }\end{array}$ & $\begin{array}{l}\text { Green marketing } \\
\text { Manage quality perception of } \\
\text { customers } \\
\text { Customers choose between new } \\
\text { and remanufactured products }\end{array}$ \\
\hline Supplier relations & $\begin{array}{l}\text { Fewer materials suppliers } \\
\text { Supplier coding of materials } \\
\text { required } \\
\text { Materials suppliers more } \\
\text { involved in product design }\end{array}$ & $\begin{array}{l}\text { Fewer components suppliers } \\
\text { Supplier coding of components } \\
\text { required } \\
\text { Component suppliers more } \\
\text { involved in product design }\end{array}$ \\
\hline Network structure & $\begin{array}{l}\text { Additional central facility } \\
\text { Decentralized repair and } \\
\text { cannibalization in OPCOs } \\
\text { Centralized separation } \\
\text { Centralized disposal }\end{array}$ & $\begin{array}{l}\text { Centralized classification/ } \\
\text { additional central facility } \\
\text { Centralized repair and } \\
\text { cannibalization } \\
\text { Centralized separation } \\
\text { Centralized disposal } \\
\text { Remanufacturing in "new } \\
\text { build" factories }\end{array}$ \\
\hline
\end{tabular}

Table 3 gives an overview of the effects of the four different phases in product recovery management on customer relations, supplier relations, and network structure.

CopyMagic is convinced that PRM would also have been attractive without the threat of legislative and regulatory changes. The estimated benefits of remanufacturing have been the largest of all PRM options. According to the company, essential factors in the economic success of PRM have been:

- the high-value of the products,

- the modular design of the products,

- the ability to upgrade products by removing outdated components and adding superior new ones,

- the fact that most products are leased,

- the high quality image of CopyMagic which convinced customers that remanufactured products are indeed "as good as new," and 
- the ability to integrate "new build" and product recovery operations in the fields of production and logistics management.

\section{BMW and IBM}

We now take a look at some of the efforts that have been undertaken by BMW and IBM, two companies that have been pro-active in product recovery management.

\section{$B M W$}

BMW has been conducting recycling research in a pilot vehicle disassembly plant in Landshut, Germany, since June 1990. Research in Landshut has concentrated on three issues: recycling of materials from existing cars, reuse of high-value parts from existing cars, and design modifications for future cars.

Materials recycling research has concentrated on improving the recyclability of plastics. Plastics constitute on average $10 \%$ of the weight of each car. Until recently, virtually all plastics were landfilled. Recycling research specifically concentrated on ways to identify, sort, regranulate, remold, and reuse these plastics. BMW aims to reuse more than $80 \%$ of all plastics. In some cases, BMW has been able to incorporate recycled plastics in the design of new parts, e.g., the luggage compartment linings on the BMW 3-series are made of recycled bumpers. ${ }^{11}$

Remanufacturing of high-value components such as engines, starter motors, and alternators has been performed by BMW for a number of years. Each component is disassembled, tested, repaired, and reassembled according to strict quality standards. Remanufactured components have the same quality and are sold with the same warranty as new parts. They are sold as "Exchange Parts" for $50 \%$ to $70 \%$ of new product prices.

Design modifications for improved product recovery include reducing the number of materials used; avoiding composite components; marking parts and components; and using two-way fasteners instead of screws and glue. The BMW $\mathrm{Zl}$, a two-seater, is an example of a car that was specifically designed for disassembly and recycling. It had an all-plastic skin that was designed to be disassembled from its metal chassis in 20 minutes. Its doors, bumpers, front, rear, and side panels were made from recyclable thermoplastics supplied by General Electric Plastics. While evaluating design for disassembly, BMW has discovered that this approach to car design has resulted in cars with improved repairability. ${ }^{12}$

Other car manufacturers-including Volkswagen, Opel, Mercedes-Benz, Peugeot-Talbot and Ford-are also involved in setting up recycling research and operations. ${ }^{13}$ 


\section{IBM}

IBM Europe has set up a product recovery management program in a number of European countries since 1990. The program was first set up in Switzerland, then in Germany, Great Britain, and the Netherlands. ${ }^{14}$

In Germany, IBM performs recovery operations in-house. In 1992, the Recycling Department of IBM Germany processed 4,000 tons of used mainframes and personal computers. This amount encompassed all equipment that IBM discarded itself (3,200 tons), and 800 tons of equipment from its customers. The majority are used mainframes. Transportation and other collection costs are the largest costs in reprocessing used mainframes. Surprisingly, current reprocessing costs are significantly higher than they were 10 years ago. This is because previous designs of mainframes contained significantly more precious metals such as gold and silver than do current ones. ${ }^{15}$

In the United Kingdom, IBM UK has offered to take back old equipment from its customers since 1991. IBM charges a fee to cover the difference between processing costs and the value of reclaimed material. Since customers are not (yet) willing to pay for reprocessing of used products, only a small proportion of used computers are collected and reprocessed. As mentioned earlier, IBM UK cooperates with the Mann Organization, a used equipment reprocessor, in its product recovery operations. In 1990, IBM UK received 1,370 tons of material and was able to recover 1,000 tons. ${ }^{16}$ IBM UK aims to reach its recycling target of $95 \%$ by $1995 .{ }^{17}$

In the Netherlands, IBM and DEC have set up a joint program in cooperation with MIREC, a Dutch equipment reprocessor, to recycle used personal computer equipment. The majority of this equipment is "off-lease" computers. IBM and DEC take care of the collection of all computers and the retrieval of reusable components. The partly disassembled computers are subsequently sent to MIREC. This company completely dismantles all computers, separates and sorts valuable and recyclable materials, and takes care of the disposal of nonrecyclable materials. For this operation, MIREC charges IBM and DEC approximately $\$ 1$ per kilo. ${ }^{18}$

\section{Managerial Implications}

Product recovery management will become an important business activity for many companies. The importance of product recovery management to the profitability of the company depends on the ability to reduce the environmental impact of used products, the capability to recover as much economic value as possible out of the used products, the ability to use product recovery management as a marketing tool, and legislation. A limited number of pro-active manufacturers have already set up systems for product recovery management and their experiences provide us with the following observations. 
First, many companies have problems acquiring accurate information on PRM issues in their business chain. This is not surprising, as many manufacturers did not consider PRM to be a (core) business activity. Required data are often scattered throughout the company or the business chain, or are not available at all. Nevertheless, companies have been able to acquire essential information by collaborating with suppliers, repair centers, reprocessors, and waste management companies. Basic information requirements deal with product characteristics, supply of used products, demand for reprocessed products, and the matching of demand and supply. Acquisition and processing of this information will require the development of new (company-wide or even business-wide) information systems.

Second, there are a number of different product recovery options. These options are interrelated as demonstrated in the CopyMagic case study, where the company employed repair, cannibalization, recycling, and remanufacturing. BMW's PRM activities include remanufacturing and recycling. Selection of PRM options depends on technical feasibility of the PRM process, availability of suitable used products, demand for reprocessed products, legislation, and available know-how in the company. Available know-how is one of the determinants in the PRM "make-or-buy" decision. An adequate solution could be to perform some PRM activities in-house and outsource the specialized PRM activities in which the company has little experience. Products and materials may go through a sequence of different phases in their life.

Third, pro-active companies set specific reuse targets for their PRM operations. BMW aims to reuse more than $80 \%$ of all plastics. IBM UK aims to reach its recycling target of $95 \%$ by 1995 . The setting of measurable objectives is a necessary condition in establishing effective PRM systems.

Fourth, in most cases PRM requires product redesign. Some general design for recycling and design for remanufacturing principles were discussed in the case study and the BMW example. These principles include design for disassembly, standardization of materials and components, coding of materials and components, recycled content, modular design, and the selection of durable and reusable materials. A by-product of design for PRM can be improved repairability. The benefits of redesigned products will largely occur after the first redesigned products have been taken back.

Fifth, PRM generally involves more cooperation for manufacturers with other organizations in the business chain. Members of this business chain include repair centers, reprocessors, and waste management companies. Cooperation opportunities arise in the areas of exchange of information, involvement in product redesign, and joint PRM operations. The number of suppliers is likely to be reduced after product redesign has taken place due to the decrease in the number of different materials and components. Manufacturers active in remanufacturing have to deal with the supplier quality paradox: suppliers that make the highest quality components may lose the most business since their 
components can be reused more often. The effect on the components' prices is not always clear.

Sixth, PRM issues could offer interesting cooperation opportunities between companies that operate in the same market. In the Netherlands, IBM and DEC have set up a joint program, in collaboration with an equipment reprocessor, to recycle used personal computers. Other opportunities exist in the area of research. On June 8, 1992, General Motors, Ford, and Chrysler launched the United States Council for Automotive Research (USCAR) to coordinate their growing list of joint R\&D projects. Joint projects include recycling research. ${ }^{19}$ Additionally, companies can cooperate to establish materials coding standards. In-mold labeling of auto parts using standard coding is expected to become universal by the late 1990 s, and to dominate vehicles entering the retired-car stream a decade later. ${ }^{20}$

Seventh, the ability of companies to successfully integrate PRM in existing systems depends on their ability to

- acquire information,

- cooperate with other companies,

- redesign products and processes if necessary,

- accurately predict and control supply of used products,

- generate demand for reprocessed products, and

- control the PRM "production" process, e.g., ensure that remanufactured products are indeed as good as new.

Companies that lease their products are generally in a more favorable position than companies that only sell products. Lease companies usually have more information on the quality and return of used products. We believe that companies with a good quality-image have a better chance of success. Convincing the customer that reprocessed products fulfill all their quality requirements seems to be all-important.

Eighth, PRM can have large influences on production, operations, and logistic management. Strategic changes may be required to deal with PRM. The case study illustrated the changes in network structure as the company progressed with PRM. Companies could be forced to acquire new skills, e.g., to perform disassembly and repair operations, or to engage in new partnerships. New information systems must be established to monitor and control PRM activities. Existing accounting systems may well be inadequate for PRM purposes. Transportation planning must take into account both forward and return flows. Warehouses must be designed to deal with two-way movements of products. Production control systems for remanufacturing must be able to deal with fundamental uncertainties in quantities, timing, and quality of used products.

Inventory control systems must be adapted. Employees must be convinced of the significance of PRM to the company and be rewarded accordingly. Although some research has been conducted in certain areas, specifically in 
models for repairable items, large research opportunities still exist. Current research by the present authors focuses on the design and analysis of production and inventory control systems, network design, and information systems. ${ }^{21}$

Should manufacturers also consider PRM when there are no legislative or regulatory changes that force them to? If so, which factors determine the success of PRM? We have identified several products and markets where PRM is being performed that are not subject to legislative or regulatory changes. For instance, remanufacturing is already being executed on a relatively large scale for: military products and components (e.g., aircraft and aircraft engines); commercial transportation-related products and components (e.g., locomotives and automotive engines); commercial heavy equipment (e.g., machine tools); and other commercial applications (e.g., medical diagnostic equipment and computers). It is remarkable that most remanufacturing operations are currently being performed by independent remanufacturers. The share of "original equipment manufacturers" in remanufacturing is relatively small.

On-going research will hopefully provide us with a better insight in the determinants of the economic attractiveness of PRM for different products and industries.

\section{References}

1. K. Bertrand, "Government Boosts Market for Recycled Products," Business Marketing (November 1990), pp. 36.

2. J. Gold, "The Pioneers," Financial World, January 23, 1990, pp. 56-58; W. D. Stephenson, "Environmentalism's Strategic Advantage," Quality (November 1991), pp. 20-23.

3. F. Cairncross, "How Europe's Companies Position to Recycle," Harvard Business Review (March/April 1992), pp. 34-45.

4. Cairncross, op. cit.; D. Rosenberg, "Designing for Disassembly," Technology Review 95/8 (November/December 1992): 17-18.

5. R. Roy and R.C. Whelan, "Successful Recycling Through Value-Chain Collaboration," Long Range Planning (August 1992), pp. 62-71.

6. H.B. Heeb, "Can Old Workhorses Still Pull Their Weight?" Manufacturing Engineering (April 1989), pp. 74-76.

7. S. Vandermerwe and M.D. Oliff, "Corporate Challenges for an Age of Reconsumption," Columbia Journal of World Business (Fall 1991), pp. 6-25.

8. G.G. Marcial, "One Man's Used Chip Is Another...," Business Week, March 1, 1993, pp. 80.

9. R.F. Huber, "Mercedes Manufacturing Strategy Is to Keep the Market Niche Full," Production (October 1991), pp. 61-63; R.D. Leaversuch, "Auto-Part Recycling Is a Top Industry Priority," Modern Plastics (March 1992), pp. 37-38.

10. Vandermerwe and Oliff, op. cit.

11. Ibid. 
12. Ibid.; B. Nussbaum and J. Templeman, "Build to Last-Until It's Time to Take Apart," Business Week, September 17, 1990, pp. 80-84.

13. Cairncross, op. cit.; Machine Design, "Leading-Edge Engineers Design For Recycling," January 24, 1991, pp. 12-14.

14. B.N. Berkman, "European Electronics Goes Green," Electronic Business, August 19, 1991, pp. 50-54.

15. F. Noe, "Recycling of Computer Becomes Costly Need," Automatiseringsgids, April 2, 1993 [in Dutch].

16. Berkman, op. cit.

17. Roy and Whelan, op. cit.

18. Volkskrant, "Philips Performs Disassembly of Computers," December 16, 1992 [in Dutch].

19. The Economist, "Lovey Dovey," June 13, 1992, pp. 69-70

20. Leaversuch, op. cit.

21. E.A. van der Laan, "On Inventory Control Models Where Items Are Remanufactured or Disposed," masters thesis in Econometrics, Erasmus University, Rotterdam, 1993. 
Copyright of California Management Review is the property of California Management Review and its content may not be copied or emailed to multiple sites or posted to a listserv without the copyright holder's express written permission. However, users may print, download, or email articles for individual use. 